\title{
ELECTRONIC NOSES FOR MONITORING BENZENE OCCUPATIONAL EXPOSURE IN BIOLOGICAL SAMPLES OF EGYPTIAN WORKERS
}

\author{
EHAB I. MOHAMED ${ }^{1}$, GIHANE I. KHALIL ${ }^{2}$, SAMIR M. ABDEL-MAGEED ${ }^{3}$, AMANI M. BAYOUMI ${ }^{3}$, \\ HEBA S. RAMADAN ${ }^{1}$, and METWALLY A. KOTB ${ }^{1}$
}

${ }^{1}$ Alexandria University, Alexandria, Egypt

Medical Biophysics Department, Medical Research Institute

${ }^{2}$ Alexandria University, Alexandria, Egypt

Chemical Pathology Department, Medical Research Institute

${ }^{3}$ Alexandria University, Alexandria, Egypt

Physics Department, Faculty of Science

\begin{abstract}
Objectives: Benzene is commonly emitted in several industries, leading to widespread environmental and occupational exposure hazards. While less toxic solvents have been substituted for benzene, it is still a component of petroleum products and is a trace impurity in industrial products resulting in continued higher occupational exposures in industrial settings in developing countries. Materials and Methods: We investigated the potential use of an electronic nose (e-nose) to monitor the headspace volatiles in biological samples from benzene-exposed Egyptian workers and non-exposed controls. The study population comprised 150 non-smoking male workers exposed to benzene and an equal number of matching non-exposed controls. We determined biomarkers of benzene used to estimate exposure and risk including: benzene in exhaled air and blood; and its urinary metabolites such as phenol and muconic acid using gas chromatography technique and a portable e-nose. Results: The average benzene concentration measured in the ambient air of the workplace of all studied industrial settings in Alexandria, Egypt; was $97.56 \pm 88.12 \mu \mathrm{g} / \mathrm{m}^{3}$ (range: $4.69-260.86 \mu \mathrm{g} / \mathrm{m}^{3}$ ). Levels of phenol and muconic acid were significantly $(\mathrm{p}<0.001)$ higher in both blood and urine of benzene-exposed workers as compared to non-exposed controls. Conclusions: The e-nose technology has successfully classified and distinguished benzene-exposed workers from non-exposed controls for all measured samples of blood, urine and the exhaled air with a very high degree of precision. Thus, it will be a very useful tool for the low-cost mass screening and early detection of health hazards associated with the exposure to benzene in the industry.
\end{abstract}

Key words:

Phenol, Muconic acid, Exhaled air, Blood, Urine, Principal Component Analysis

Received: April 4, 2012. Accepted: November 27, 2012.

Part of this work was presented in abstract form in the Annual Meeting of the German Biophysical Society (DGfB) held in Göttingen, Germany, 23-26 September, 2012. This work was supported by a research grant from the Science and Technology Development Fund (STDF), Egyptian Ministry of Higher Education and Scientific Research [Project ID \#963, 2010/2012] and by Airsense Analytics GmbH, Schwerin, Germany.

Corresponding author: E.I. Mohamed, Medical Biophysics Department, Medical Research Institute, Alexandria University, 165 El-Horreya Avenue, 21561 Alexandria, Egypt (e-mail: eimohamed@yahoo.com). 


\section{INTRODUCTION}

Benzene, a major monocyclic aromatic hydrocarbon, is still a component of petroleum products and is a trace impurity in a variety of industrial and commercial processes in the manufacturing of lubricants, detergents, rubber, dyes and pesticides [1,2]. The exposure of workers to benzene occurs through inhalation and/or absorption via the skin [2]. Benzene is metabolized in the human body to phenols, which can be detected in the urine of exposed workers [3].

According to the American Conference of Governmental Industrial Hygienists (ACGIH), the maximum assigned threshold limit value of benzene, as a time-weighed average concentration, in a normal 8-hour workday and a 40-hour workweek is $30 \mathrm{mg} / \mathrm{m}^{3}$. Acute exposure to benzene can cause dizziness, euphoria, giddiness, headache, nausea, staggering gait, weakness, drowsiness, respiratory and gastrointestinal irritation, pulmonary edema and pneumonia, convulsions and paralysis [2,4]. Benzene can also cause irritation to the skin, eyes and mucous membranes. Moreover, chronic exposure to benzene can cause fatigue, nervousness, irritability, blurred vision, and labored breathing. Repeated skin contact can cause redness, blistering, and scaly dermatitis $[2,4,5]$.

Recent studies showed significant hematological disorders, chromosomal aberrations as well as relatively high concentration of phenol in 24-hour urine samples due to exposure to benzene in chemical industry workers [4-7]. Furthermore, blood disorders may lead to anemia and other diseases causing a significant reduction in working capacity and activity of workers, loss of working hours, and the increase in the costs of medical care of the affected workers [4].

Recently, there has been an increasing interest in the development of Electronic Nose (e-nose) technology, which is an electronic instrument capable of detecting and recognizing many gaseous vapors and odors [8]. In an e-nose there are three components: a) a sampling conditioning unit used to collect samples of air containing the odoriferous volatiles from the headspace above the sample; b) a test chamber housing the sensor array; and c) a processing unit which analyzes the sensor response patterns using various feature extraction and classification statistical algorithms [8-10].

The objectives of the present study were to investigate the potential use of an e-nose to monitor the headspace volatiles in biological samples from benzene-exposed Egyptian workers and non-exposed controls and to investigate causes of these odors in relation to their biochemical parameters by conventional chemical analysis techniques.

\section{SUBJECTS AND METHODS}

\section{Subjects}

Adult non-smoking male workers in printing, textile and petrochemical industries exposed to benzene in Alexandria, Egypt ( $\mathrm{N}=150$, age range: $24-60$ years, and mean age \pm SD: $34.12 \pm 4.35$ years), as well as sex- and agematched non-smoking non-exposed controls $(\mathrm{N}=150$, age range: $24-59$ and mean age \pm SD: $33.91 \pm 3.75$ years) were asked to freely volunteer to participate in the study. All participants were instructed about the study aim, procedures and benefits and asked to sign informed consent prior to their inclusion in the study. All participants were subjected to complete history taking and thorough physical examination by expert physicians at the Internal Medicine Department, Medical Research Institute, Alexandria University, Egypt to determine their occupational history, food and smoking habits, and health status. The conditions of their work environment, working time and work shift were also recorded. The Ethics Committee of the Medical Research Institute, Alexandria University; approved the study protocol and all experimental procedures are in accordance with the Helsinki Declaration of 1975, as revised in 1983. 


\section{METHODS}

\section{Sampling technique}

Blood, 1-2-hour urine fraction and exhaled air samples were collected after a working shift of 8-hours from all participants into disposable plastic tubes/containers in triplicates at the Chemical Pathology Department, Medical Research Institute, Alexandria University, Egypt. A single investigator, who was unaware of the individuals' health status or diagnosis, collected samples randomly for subsequent measurements. A simple technique was modified for collecting mouth-exhaled air samples from all participants into disposable sterile plastic sacks with a tight closing seal. All subjects were instructed to take a deep breath through the nose and blow once to fill a sack through the mouth by using a one-way valve, as detailed in an earlier study [11].

\section{Gas Chromatography (GC) analysis}

The concentrations of benzene, phenol and muconic acid in fresh blood and urine samples of all participants were analyzed. The first container samples of both studied groups were analyzed using a gas chromatograph (Auto System XL, Perkin Elmer, USA). Ten milliliters of the headspace of each sealed tube was aspired using a gas tight syringe and injected immediately into the GC, where oven temperature was kept at $29^{\circ} \mathrm{C}$ for 2 min and then programmed to increase to $56^{\circ} \mathrm{C}$ at $5^{\circ} \mathrm{C}$ increments. The injector and detector temperatures were set at $180^{\circ} \mathrm{C}$ and $200^{\circ} \mathrm{C}$, respectively. $\mathrm{H}_{2}$ and $\mathrm{N}_{2}$ were set at $45 \mathrm{~cm} / \mathrm{s}$ flow rates and areas under peaks were calculated using the driving software. Reference standard of benzene was prepared and measured to calculate benzene concentration in each sample $[12,13]$.

\section{E-Nose analysis}

The second container samples were analyzed at the Medical Biophysics Department, Medical Research Institute, Alexandria University, Egypt, using a commercially available portable e-nose (PEN3, Airsense Analytics $\mathrm{GmbH}$, Schwerin, Germany) with an array of 10 different metal-oxide sensors that measure independently and register continuously relative changes in conductance due to a vapor or odor during an experiment. Odors in the headspace (i.e. the space over blood or urine samples and exhaled air in sacks) of each sealed container were carried by the carrier gas (e.g. dry air) to the array of sensors through the inlet at a rate of $400 \mathrm{ml} / \mathrm{min}$. Solenoid valves alternately switched the pure carrier gas and the headspace sample vapor, and the differences in the sensor output were recorded.

Following a $50 \mathrm{~s}$ flushing time and a $10 \mathrm{~s}$ zero point trim time periods each, sealed container was connected subsequently to the e-nose inlet through a teflon tubing $(3 \mathrm{~mm}$ internal diameter) connected to a long luer-lock needle (size 20G) perforating the seal of the container, for a $60 \mathrm{~s}$ measurement period. A second short needle also perforating the seal was used to connect the container to room air. During the flushing period, sensors were rinsed with zero-gas and their signals moved back to the baseline $(\mathrm{G} /$ $\mathrm{G}_{\mathrm{o}}=1$ ). The software interacts with the user by displaying the correct time points to connect and disconnect the sample to and from the e-nose inlet. All measurements were repeated twice and sensor response patterns were extracted manually and further analyzed at the same point of time (i.e. at $45 \mathrm{~s}$, when patterns were stable in the plateau region) using specific software package WinMuster 1.6.2 provided by the manufacturer (Airsense Analytics $\mathrm{GmbH}$, Schwerin, Germany).

\section{Data analysis}

The Principal Component Analysis (PCA) analyzed all e-nose sensor response patterns, which is an orthogonal linear and unsupervised multivariate statistical method that reduces the dimensionality of data from the 10 sensor patterns to a two-dimensional coordinate system. That is, for any projection of these data, the first two principal 
components with the highest variance (i.e. principal component \#1 and \#2) are set automatically by the software on the X-Y coordinates, which gives rise to a cluster plot representing the original data. PCA is theoretically the optimum transform for given data in least square terms [14-16].

Analyses of all data were carried out using the statistical software package StatView ${ }^{\circledR}$ 5.0 (SAS Inst., Cary, NC, USA). Descriptive statistics were calculated for the mean \pm SD of physical and chemical measurements of biological samples of all participants using chemical analysis techniques. Mean parameter values of benzeneexposed and non-exposed control groups were compared using two-tailed Student's t-test of significance. Differences were considered significant at $\mathrm{p}<0.05$.

\section{RESULTS}

The average benzene concentration measured in the ambient air of the workplace of all studied industrial settings in Alexandria, Egypt; was $97.56 \pm 88.12 \mu \mathrm{g} / \mathrm{m}^{3}$ (range: 4.69-260.86 $\mu \mathrm{g} / \mathrm{m}^{3}$ ). These levels are in accordance with values measured for similar industrial settings in an earlier study [17]. Exposure to benzene in the workplace was found to be directly proportional to e-nose average relative 10 -sensor responses $\left(\mathrm{G} / \mathrm{G}_{\mathrm{o}}\right)$ for all urine samples of exposed workers, that is lower levels of benzene concentrations in the workplace, as $4.69 \mu \mathrm{g} / \mathrm{m}^{3}$, were associated with lower sensor responses, as those shown in Figure 1a. At the same time, higher levels of benzene concentrations in the workplace, as $260.86 \mu \mathrm{g} / \mathrm{m}^{3}$, were associated with much higher relative e-nose sensor responses of their urine samples, as those shown in Figure 1b.

The influence of benzene exposure in industry was determined in blood for all studied workers as well as in the urinary excretion of phenol and muconic acid, two common metabolites of benzene in human subjects. The full physical and chemical characteristics of blood and urine

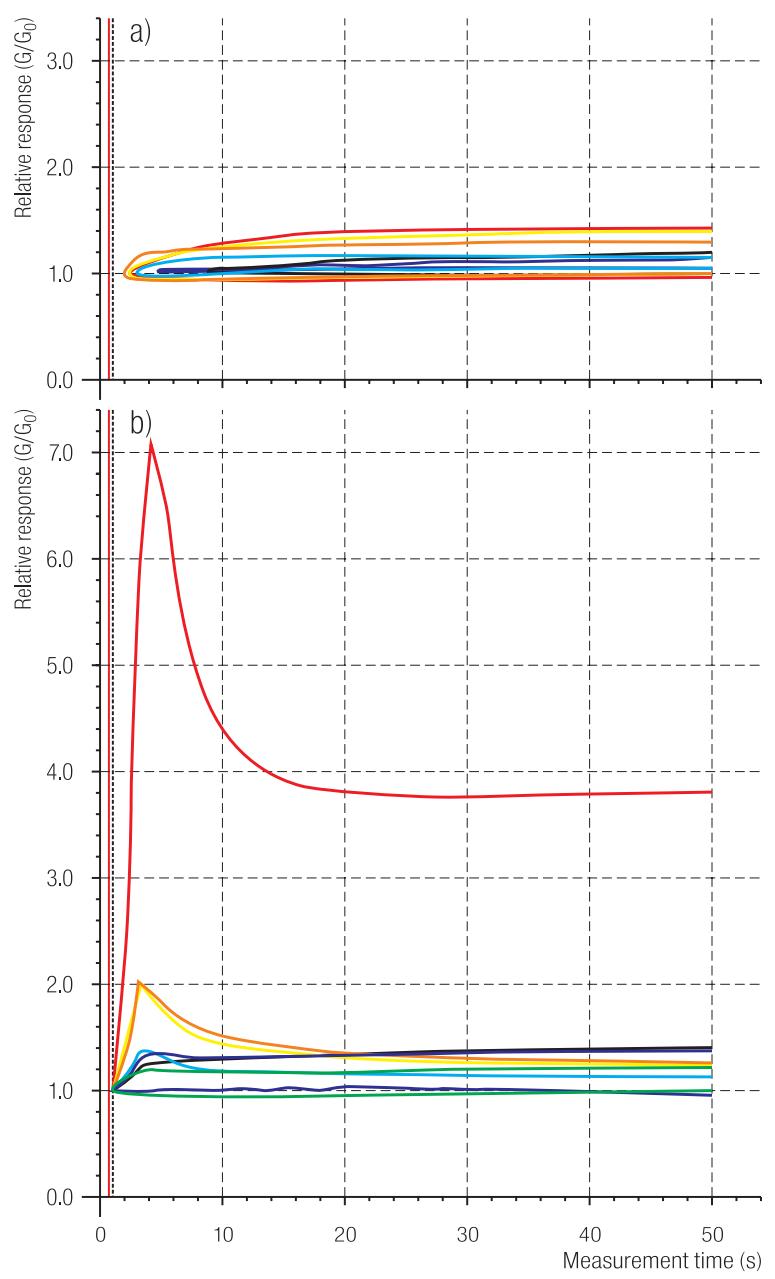

Relative sensor responses were found to be directly proportional to worker's exposure to benzene as estimated by its phenol and muconic acid metabolites determined using Gas Chromatography Technique.

Fig. 1. Typical 10-sensor relative responses $\left(\mathrm{G} / \mathrm{G}_{\mathrm{o}}\right)$ of an e-nose measurement time-plot for: a) a urine sample of a worker exposed to benzene at a low concentration of $4.69 \mu \mathrm{g} / \mathrm{m}^{3}$ and b) a urine sample of a worker exposed to benzene at a high concentration of $260.86 \mu \mathrm{g} / \mathrm{m}^{3}$

samples for all participants are detailed in Table 1. Although benzene was not detected in any of the blood samples from both groups or in the urine samples of nonexposed controls, it was only detected in the urine of benzene-exposed workers; however, phenol and muconic acid were present in significantly higher amounts $(p<0.001)$ in both the blood and urine of benzene-exposed workers as compared to non-exposed controls. 
Table 1. Descriptive and biochemical parameters of benzene-exposed male workers as compared to non-exposed controls

\begin{tabular}{|c|c|c|}
\hline \multirow{2}{*}{ Parameters } & \multicolumn{2}{|c|}{ Studied groups } \\
\hline & benzene-exposed & non-exposed controls \\
\hline Respondents (n) & 150 & 150 \\
\hline Age (year) & $34.12 \pm 4.35$ & $33.91 \pm 3.75$ \\
\hline Weight (kg) & $84.25 \pm 13.77$ & $78.01 \pm 18.82$ \\
\hline Height (m) & $1.72 \pm 0.05$ & $1.73 \pm 0.07$ \\
\hline Body Mass Index & $31.28 \pm 4.13$ & $31.51 \pm 6.24$ \\
\hline Benzene in blood (ng/l) & ND & ND \\
\hline Benzene in urine (ng/l) & $47.56 \pm 5.66$ & ND \\
\hline Phenol in blood (mg/l) & $6.08 \pm 1.13^{*}$ & $0.22 \pm 0.02$ \\
\hline Phenol in urine (mg/g creatinine) & $0.42 \pm 0.07^{*}$ & $0.07 \pm 0.01$ \\
\hline Muconic acid in blood (mg/l) & $1.17 \pm 0.14^{*}$ & $0.02 \pm 0.01$ \\
\hline Muconic acid in urine (mg/g creatinine) & $0.95 \pm 0.13^{*}$ & $0.06 \pm 0.01$ \\
\hline
\end{tabular}

ND - not detectable.

Values are expressed as mean \pm SD.

$* \mathrm{p}<0.001$ as compared to non-exposed control group.

Figure 2 is a typical cluster plot by PCA of exhaled air sample measurements using e-nose for benzene-exposed workers and non-exposed controls, where both principal components \#1 and \#2 explained more than $87 \%$ of the variance in signals. A clear distinction between both groups is evident, meaning the e-nose was capable of identifying samples from each group with no false-positive (non-exposed controls) or false-negative (benzene-exposed) results. This lends support to the fact that the volatiles found in the air exhaled by workers exposed to benzene are significantly different from those for non-exposed controls. Similar cluster plots by PCA of blood and urine samples for benzene-exposed and non-exposed controls are also shown in Figures 3 and 4 , yet with higher explanation of the variance in signals (i.e. $95 \%$ for blood samples and $91 \%$ for urine samples, respectively). Regression analysis showed a very high significant correlation between phenol in both blood and urine of exposed workers and average e-nose relative sensor responses $(\mathrm{R}=0.99$ and 0.96 , respectively; $\mathrm{p}<0.001$ for both associations). Even higher statistically significant correlations were found to occur between muconic acid levels in both blood and urine of exposed workers, and average e-nose sensor responses ( $\mathrm{R}=0.99$ and 0.98 , respectively; $\mathrm{p}<0.001$ for both associations).

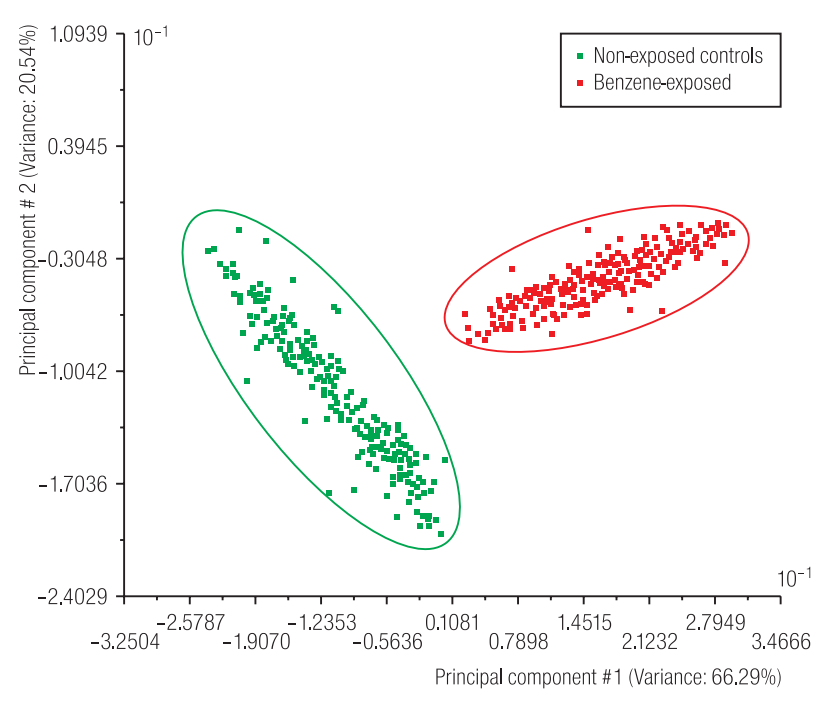

Fig. 2. Plot of principal component \#1 against principal component \#2 for an electronic nose provided with an array of 10 metal-oxide sensors when applied to exhaled air samples from male workers exposed to benzene and non-exposed controls 


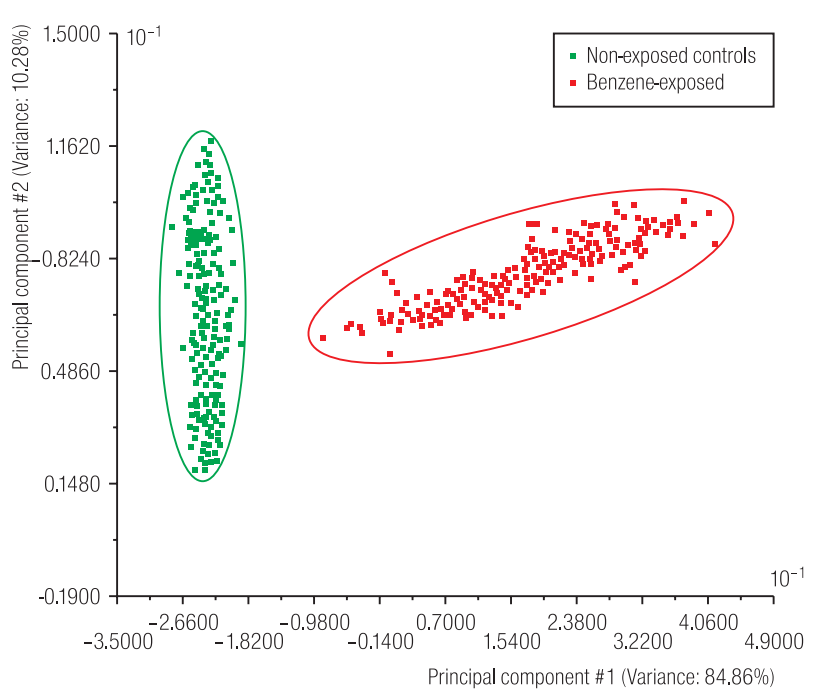

Fig. 3. Plot of principal component \#1 against principal component \#2 for an electronic nose provided with an array of 10 metal-oxide sensors when applied to head space of blood samples from male workers exposed to benzene and non-exposed controls

\section{DISCUSSION}

Benzene is commonly emitted in several industrial settings, leading to widespread environmental and occupational exposure hazards. While less toxic solvents have been substituted for benzene, it is still a component of petroleum products and is a trace impurity in many industrial products resulting in continued sub- to low-occupational exposures, though higher exposures occur in industrial settings of developing countries $[1,2,17,18]$. Under conditions prevailing at the workplace, benzene is absorbed by inhalation, although dermal absorption of liquid benzene is also significant [2]. Benzene metabolism has been extensively studied in various animal models, in vitro incubations, and by theoretical calculations [2-7], with evidences that it is impossible to distinguish between occupational and environmental exposure when the benzene level in the workplace is less than $100 \mu \mathrm{g} / \mathrm{m}^{3}$ [19].

Approximately one-third of retained benzene is excreted rapidly in urine as conjugate phenol and dihydroxy phenols $[18,19]$, while the remainder is further degraded to be

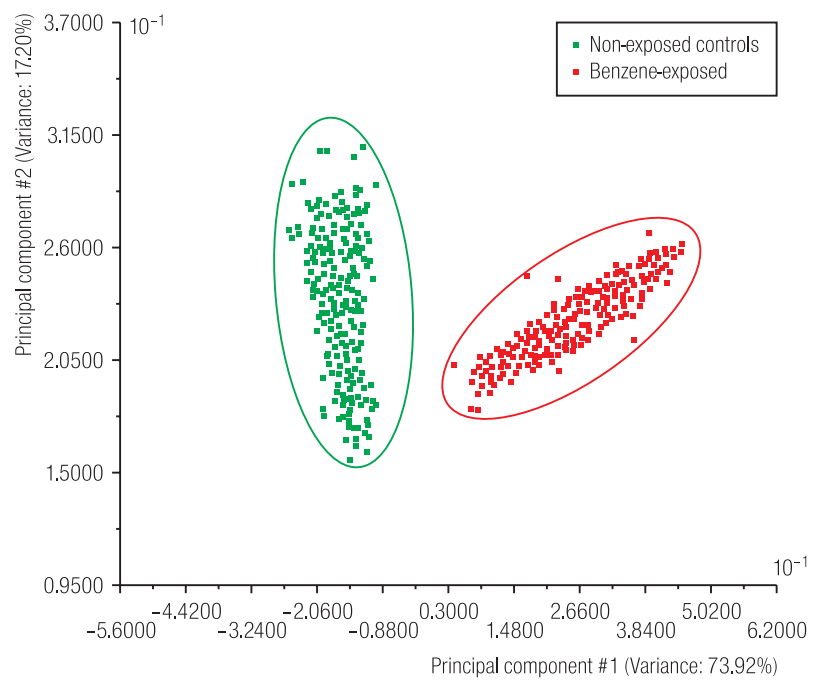

Fig. 4. Plot of principal component \#1 against principal component \#2 for electronic nose provided with an array of 10 metal-oxide sensors when applied to head space of urine samples from male workers exposed to benzene and non-exposed controls

incorporated in tissues or exhaled as $\mathrm{CO}_{2}$ [20]. These observations are in line with findings of the present study, where both phenol and muconic acid were present in the blood and urine of Egyptian workers exposed to benzene in significant amounts as compared to non-exposed controls (Table 1).

The relative contribution of each benzene metabolite to the adverse health effects of benzene, both alone and in various combinations is still a subject of some debate [18]. Several studies have shown that benzene metabolites related to muconic acid and hydroquinone are more genotoxic than phenol or compounds related to catechol [3,21,22]. In particular, growing evidence suggests that metabolites derived from hydroquinone, including 1,2,4-benzenetriol and particularly 1,4-benzoquinone, are highly toxic [3]; however, other studies have shown synergistic effects between combinations of hydroquinone and other metabolites, including phenol and catechol [22].

The recent availability of commercial e-nose technology for detecting and characterizing headspace odors has provided a fast viable technique that may successfully replace laboratory-based conventional methods for detecting blood in the urine of nephropathic individuals, monitoring and 
classifying metabolic clearance and the insurgence of nephropathy in type 2 diabetic patients, and for qualitatively evaluating the components of odor of urine [23-25]. It has shown also potentials for diagnosing chronic rhinosinusitis by examining patients' nose-exhaled air samples [11].

The average e-nose relative 10-sensor responses for all urine samples of exposed Egyptian workers were directly proportional to benzene concentration in the workplace; lower levels of benzene concentrations were associated with lower e-nose sensor responses, while higher levels were associated with much higher e-nose relative sensor responses to their urine samples (Figure $1 \mathrm{a}$ and $\mathrm{b}$ ). Phenol and muconic acid present in the blood and urine of benzene-exposed workers at higher levels as compared to the levels prevailing in non-exposed controls were responsible for the marked distinction shown in the PCA cluster plots of exhaled-air, blood and urine sample measurements by enose (Fig. 2-4); this deduction was supported by regression analysis, which showed a very high significant correlation between phenol and muconic acid in both blood and urine of benzene-exposed workers and average e-nose relative sensor responses. These observations are in line with recent findings by Rappaport et at. [26], who showed noticeable metabolism of benzene to phenol and muconic acid at benzene concentrations in the air below $0.3 \mathrm{mg} / \mathrm{m}^{3}$.

The e-nose classified and identified correctly all biological samples from each group with no false-positive (nonexposed controls) or false-negative (benzene-exposed) results, which can form a precise reference database for the purpose of further identification of unknown exposed workers. Although the analysis of phenol and muconic acid in exhaled air samples using standard GC technique could not be done, the results of PCA cluster analysis by e-nose differentiating exposed workers from non-exposed controls in Figure 2 were identical to those obtained for blood and urine samples (Figures 3 and 4, respectively), and it seems reasonable to assume that e-nose method outweighs the GC technique in many ways. The e-nose technique is rapid, easy, does not require any sample treatment or heating, and its sensitivity is similar to that of GC quantitative technique.

Thus, the e-nose technology represents a very useful tool for the low-cost mass screening and early detection of health hazards associated with the exposure to benzene in the industry. This will enable treating confirmed benzeneexposed workers with related pathologies quickly using standard methods prior to the aggravation of their health status. The social and financial rewards of such test are immeasurable, since it will prevent the reduction of employee work efficiency attributable to adverse health effects of benzene exposure, and the costs of worker absenteeism and medical treatment.

The e-nose technology successfully classified and identified workers exposed to benzene from non-exposed controls with no false-positive or false-negative results for all measured exhaled air, blood and urine samples to a very high degree of precision. Thus, it will be a very useful tool for the low-cost mass screening and early detection of health hazards associated with the exposure to benzene in the industry according to the data.

\section{REFERENCES}

1. Uzma N, Salar BM, Kumar BS, Aziz N, David MA, Reddy VD. Impact of organic solvents and environmental pollutants on the physiological function in petrol filling workers. Int J Environ Res Public Health 2008;5:139-46.

2. U.S. Department of Health and Human Services. Occupational safety and health guideline for benzene: Potential human carcinogen. Benzene. Atlanta: Public Health Service CDC; 1988. p. 1-6.

3. Rothman N, Bechtold WE, Yin SN, Dosemeci M, Li GL, Wang YZ, et al. Urinary excretion of phenol, catechol, hydroquinone, and muconic acid by workers occupationally exposed to benzene. Occup Environ Med 1998;55:705-11. 
4. Schnatter RA, Kerzic PJ, Zhou Y, Chen M, Nicolich MJ, Lavelle K, et al. Peripheral blood effects in benzene-exposed workers. Chem Biol Interact 2010;184:174-81.

5. Zhang L, McHale CM, Rothman N, Li G, Ji Z, Vermeulen $\mathrm{R}$, et al. Systems biology of human benzene exposure. Chem Biol Interact 2010;184:86-93.

6. Swaen GM, van Amelsvoort L, Twisk JJ, Verstraeten E, Slootweg R, Collins JJ, et al. Low level occupational benzene exposure and hematological parameters. Hem Biol Interact 2010;184:94-100.

7. Shen M, Zhang L, Lee KM, Vermeulen R, Hosgood HD, $\mathrm{Li} \mathrm{G}$, et al. Polymorphisms in genes involved in innate immunity and susceptibility to benzene-induced hematotoxicity. Exp Mol Med 2011;43:374-8.

8. Freund MS, Lewis NS. A chemically diverse conducting polymer-based "electronic nose". Proc Natl Acad Sci USA 1995;92:2652-6.

9. Gardner JW, Bartlett PN. E-noses: Principles and Applications. Oxford: Oxford University Press; 1999. p. 67-100.

10. Toko K. Biomimetic Sensor Technology. Cambridge: Cambridge University Press; 2000. p. 92-111.

11. Mohamed EI, Bruno E, Linder R, Alessandrini M, Di Girolamo A, Pöppl SJ, et al. A Novel Method For Diagnosing Chronic Rhinosinusitis Based on an Electronic Nose. Otorrinolaringol Ibero Am 2003;30:447-57.

12. Kivistö H, Pekari K, Peltonen K, Svinhufvud J, Veidebaum T, Sorsa M, et al. Biological monitoring of exposure to benzene in the production of benzene and in a cokery. Sci Total Environ 1997;199:49-63.

13. Mohamed EI, Maher HM, Shabaan AM, Hussein FM. Electronic nose technology for the accurate detection of estrus by monitoring changes in perineal odors in dairy cows. J Biophys Biomed Sci 2009;2:128-33.

14. Manly BFT. Multivariate Statistical Methods. London: Chapman \& Hall; 1986.

15. Haykin S. Neural Networks: a Comprehensive Foundation. New York: MacMillan Publishing Company; 1994.
16. Everitt B. Cluster analysis is a generic term for a wide range of numerical methods for examining data. Stat Methods Med Res 2004;13:343-5.

17. Perbellini L, Faccini GB, Pasini F, Cazzoli F, Pistoia S, Rosellini R, et al. Environmental and occupational exposure to benzene by analysis of breath and blood. Br J Ind Med 1988;45:345-52.

18. Weisel CP. Benzene exposure: an overview of monitoring methods and their findings. Chem Biol Interact 2010;184:58-66.

19. Brugnone F, Perbellini L, Romeo L, Bianchin M, Tonello A, Pianalto G, et al. Benzene in environmental air and human blood. Int Arch Occup Environ Health 1998;71:554-9.

20. Hanke J, Dutkiewicz T, Piotrowski J. Absorption of benzene through the skin in man. Med Pr 1961;12:413-26.

21. Anwar WA, Au WW, Legator MS, Sadagopa Ramanujam VM. Effect of dimethyl sulfoxide on the genotoxicity and metabolism of benzene in vivo. Carcinogenesis 1989;10: 441-5.

22. Irons RD, Stillman WS, Colagiovanni DB, Henry VA. Synergistic action of the benzene metabolite hydroquinone on myelopoietic stimulating activity of granulocyte/macrophage colony-stimulating factor in vitro. Proc Natl Acad Sci USA 1992;89:3691-5.

23. Ping W, Yit T, Haibao X, Farong S. A novel method for diabetes diagnosis based on electronic nose. Biosens Bioelectron 1997;12:1031-6.

24. Di Natale C, Mantini A, Macagnano A, Antuzzi D, Paolesse R, D'Amico A. Electronic nose analysis of urine samples containing blood. Physiol Meas 1999;20:377-84.

25. Mohamed EI, Linder R, Perriello G, Di Daniele N, Pöppl SJ, De Lorenzo A. Predicting type 2 diabetes using an electronic nose-based artificial neural network analysis. Diab Nutr Metab 2002;15:215-21.

26. Rappaport SM, Kim S, Lan Q, Li G, Vermeulen R, Waidyanatha $\mathrm{S}$, et al. Human benzene metabolism following occupational and environmental exposures. Chem Biol Interact 2010;184:189-95.

This work is available in Open Access model and licensed under a Creative Commons Attribution-NonCommercial 3.0 Poland License - http://creativecommons.org/ licenses/by-nc/3.0/pl/deed.en. 